\title{
Lectures croisées de l'œuvre de Michel Houellebecq, sous la direction d'Antoine JURGA et Sabine VAN WESMAEL
}

\section{Aron Verga}

\section{(2) OpenEdition}

\section{Journals}

Édition électronique

URL : http://journals.openedition.org/studifrancesi/16753

DOI : 10.4000/studifrancesi. 16753

ISSN : 2427-5856

\section{Éditeur}

Rosenberg \& Sellier

\section{Édition imprimée}

Date de publication : 1 juillet 2019

Pagination : 196-197

ISSN : 0039-2944

\section{Référence électronique}

Aron Verga, "Lectures croisées de l'œuuvre de Michel Houellebecq, sous la direction d'Antoine JuRga et Sabine van WESMAEL », Studi Francesi [En ligne], 187 (LXIII | I) | 2019, mis en ligne le 01 juillet 2019, consulté le 25 janvier 2021. URL : http://journals.openedition.org/studifrancesi/16753 ; DOI : https:// doi.org/10.4000/studifrancesi. 16753

Ce document a été généré automatiquement le 25 janvier 2021.

\section{(†) $\odot$

Studi Francesi è distribuita con Licenza Creative Commons Attribuzione - Non commerciale - Non opere derivate 4.0 Internazionale. 


\section{Lectures croisées de l'œuvre de Michel Houellebecq, sous la direction d'Antoine JURGA et Sabine VAN WESMAEL}

Aron Verga

\section{RÉFÉRENCE}

Lectures croisées de l'œuvre de Michel Houellebecq, sous la direction d'Antoine JURGA et Sabine VAN WESMAEL, Paris, Classiques Garnier, 2017, «Rencontres»174, 301 pp.

1 Questa raccolta di testi critici su Michel Houellebecq vuole rispondere alla domanda in quarta di copertina: "Quel accueil la critique universitaire réserve-t-elle à une littérature à ce point inscrite dans des débats d'opinion idéologiques et médiatiques?». Sino a pochi anni fa Houellebecq era poco apprezzato dal mondo accademico, ma con il passare del tempo si è cominciato a indagare sulle ragioni del suo successo. Il presente testo vuole colmare, attraverso una serie di sguardi molteplici e internazionali, l'assenza di un volume dedicato alla ricezione delle opere di Houellebecq, il quale se ne rammaricava già in Ennemis publics (2008). Tuttavia, la vera ambizione di Antoine Jurga e Sabine van Wesmael è di offrire una possibilità «de mieux lire Michel Houellebecq» (p. 10), eliminando pertanto la diffidenza che aleggia su ogni sua pubblicazione e consentendogli di avere un posto tra i principali autori contemporanei. I curatori notano inoltre come si sia venuto a creare «un certain nombre de fidèles» (p. 9) attorno alla figura dello scrittore, facendo presente come Houellebecq sia più apprezzato all'estero che in Francia.

2 Il volume è diviso in due parti, «Réception productive» e "Réception critique», finalizzate a fornire un'immagine dell'impatto di Michel Houellebecq sulla letteratura francese e mondiale. Ad aprire la prima parte sono due scritti dei curatori, il primo, 
Michel Houellebecq, auteur classique? di Antoine JURGA, affronta la questione dell'incapacità della letteratura contemporanea a opporsi alla realtà $o$ a dare delle risposte ai lettori; il secondo, Michel Houellebecq, figure de roman di Sabine VAN WESMAEL, sottolinea come Houellebecq sia utilizzato come personaggio romanzesco in testi di altri autori (Djian, Mérot, Marienské, Nabe) al fine di omaggiarlo, benché venga descritto in maniera buffa e assurda. Samuel ESTIER analizza i pastiches dell'autore in quanto illustrano e caricaturizzano la sua presunta mancanza di stile (Houellebecq pastiché et canonisé). Ania WROBLEWSKI, in Les seuls blancs à Châtelet-les-Halles. Richard Millet, Michel Houellebecq et les limites du nationalisme français, riflette sulla questione della libertà d'espressione dopo gli attentati parigini del 7 gennaio 2015, di come arte e letteratura siano influenzate da un sentimento nazionalista nel momento in cui attualità politica e provocazione artistica si incontrano. In «Personne n'a comme Houellebecq l'intelligence du monde contemporain». Bernard Maris lecteur de Houellebecq, Chloé MONEY evidenzia come il saggio di Maris (Houellebecq économiste, Flammarion, 2014) mettesse in rilievo l'importanza dell'opera di Houellebecq, difendendolo dalle accuse di cinismo e misoginia, poiché si poneva di fronte ai problemi concreti dell'epoca contemporanea (sofferenza sul posto di lavoro, consumismo, sensazione continua di vuoto e di mancanza). In Le désir d'être écrit. Étude comparative de deux modèles d'écriture computationnels dans "La possibilité d'une île" de Michel Houellebecq et "La théorie de l'information" d'Aurélien Bellanger, Emmanuel BUZAY presenta gli aspetti comuni ai due testi ispirati dalle strutture algoritmiche dell'informatica e sottolinea gli aspetti di un immaginario che ripensa i limiti di un'umanità fondata su un concetto di scrittura teleologico e sui suoi miti. In Autour de "La possibilité d'une île". Lorsque la réception pénètre les œuvres, Alice BOTTARELLI s'interroga sul rapporto tra scrittore e personaggi, un gioco di echi sostenuto dallo stesso Houellebecq, il quale ne aumenta l'ambiguità nei propri testi. Jitske VAN DER GOOT, in La distance ironique dans les romans de Houellebecq et Grunberg, sottolinea come i due autori, attraverso ironia, satira e iperboli, condividano una poetica controversa e un cinismo spietato, presentando quindi una società in decomposizione, un'immagine talvolta grottesca ma reale. Carine RoucAN pone in rilievo l'importanza di conoscere a fondo l'opera di Huysmans per comprendere a pieno l'ultimo libro di Houellebecq, il cui tema non sarebbe il mondo politico, bensì il concepimento del romanzo (J.-K. Huysmans, un personnage clé de "Soumission").

3 La seconda parte inizia con il testo di Isabelle DUMAs Houellebecq au Canada et sur la toile, in cui si analizza la ricezione dei lavori di Houellebecq da parte degli accademici, della stampa e persino della Rete; infatti la Dumas gestisce un blog sull'autore francese dal 2013. In La réception de l'œuvre houellebecquienne sur le marché argentin, María Julia ZAPARART si concentra sul confronto delle traduzioni spagnole con le versioni originali. Miguel Amores sottolinea come la critica ispanica abbia suggerito l'esistenza di una dimensione extraletteraria dell'autore, ossia il fenomeno Houellebecq: non solo l'eterogeneità di tale aspetto obbliga la critica a ripensare la nozione di ricezione critica, ma Houellebcq, in quanto personaggio mediatico, è divenuto elemento strutturale per analizzare la sua opera (La critique espagnole certifie le phénomène Houellebecq). In Colombie et Mexique. L'Amérique latine reçoit Michel Houellebecq, Carlos TELLO analizza la mancanza di saggi dedicati a Houellebecq nei due paesi, concentrandosi dunque su una manciata di articoli pubblicati tra il 2006 e il 2013. Les lecteurs italiens de Houellebecq di Elisabetta SIBILIO ricompone la situazione dell'opera di Houellebecq in Italia: esamina soprattutto l'attenzione mediatica rivolta a Soumission, 
soffermandosi in particolar modo sul tempo trascorso tra la pubblicazione dell'originale e della traduzione. Svetlana SHEYPAK, attraverso lo studio dei commenti di lettori, degli articoli critici e universitari, evidenzia alcune divergenze tra grande pubblico e critica nella ricezione di Houellebecq in Russia (Houellebecq lu en Russie). In Michel Houellebecq, l'écrivain le plus important de la Norvège?, Geir UVsLøKK sottolinea come Houellebecq fosse poco conosciuto in Norvegia prima del gennaio 2015; pertanto, lo studio della ricezione, fino a quella data, si basa sulla lettura meticolosa delle traduzione. Successivamente invece, i lettori sono aumentati, Houellebecq è diventato uno degli autori più rinomati in Norvegia e sono comparse delle critiche superficiali e sempliciste accanto ad analisi di critica letteraria e accademica. Infine, Louis BOUSQUET (Réception du roman "Soumission" dans la presse américaine) prende in esame decine di articoli apparsi negli Stati Uniti per comprendere come è stato accolto Soumission sul territorio nordamericano: dalle reazioni del pubblico al punto di vista su Islam, democrazia e futuro delle donne a come sono percepiti lo stile e la prosa di Houellebecq. 